$\mathrm{AB} 1124$

A UK STUDY: VOCATIONAL EXPERIENCES OF YOUNG ADULTS WITH JUVENILE IDIOPATHIC ARTHRITIS

L.E. Lunt ${ }^{1,2}$, M. Bezzant ${ }^{3}$, A. Bosworth ${ }^{3}$, J.E. McDonagh ${ }^{1,2}$, K. Hyrich $^{1,2}$ W. Thomson ${ }^{2,4}, \underline{\text { S. Verstappen }}{ }^{1,2}$. ${ }^{1}$ Arthritis Research UK Centre for Epidemiology Centre for Musculoskeletal Research, Manchester Academic Health Science Centre, The University of Manchester, ${ }^{2} \mathrm{NIHR}$ Manchester Biomedical Research Centre, Manchester University NHS Foundation Trust, Manchester Academic Health Science Centre, Manchester, ${ }^{3}$ National Rheumatoid Arthritis Society (NRAS), Maidenhead; ${ }^{4}$ Arthritis Research UK Centre for Genetics and Genomics, Centre for Musculoskeletal Research, The University of Manchester, Manchester, UK

Background: Little is known about the experiences of young adults living with Juvenile Idiopathic Arthritis (JIA) preparing for employment and career development.

Objectives: The purpose of this study was to understand the impact JIA has on career planning and early employment experiences of young adults (16-30 years).

Methods: Using existing literature (including grey literature), an online survey (consisted of 152 questions, 29 items related to young adults two of which were free text questions) was developed and sent to UK National Rheumatoid Arthritis Society (NRAS) members and distributed to non-members via social media tools including Facebook, Twitter and HealthUnlocked. Data collected included views and experiences in career planning and employment. The data pertaining to young adults are presented here.

Results: Of 1241 respondents 19 were young adults with JIA (range 16-30 years), $89 \%$ were female and $84 \%$ had university or equivalent qualifications. Due to incomplete responses there is missing data on all 19 young adults. 4/13 young adults were studying at university, $9 / 13$ were in paid employment. $9 / 17$ respondents reported their school did not offer additional work-related activities to students with disabilities and/or additional needs. 10/14 young adults felt their school did not provide advice about coping with possible limitations on placements/traineeships due to their arthritis. 11/14 respondents did consider their condition when thinking about future career plans e.g. "I wanted to work as a ranger or similar for the National Trust but it's a fairly physically demanding job and I knew my joints would suffer so I changed track slightly". However, 8/14 felt their career advisors at school/university did not take their arthritis into account e.g. "I had to cease my physiotherapy master's degree as my arthritis got too bad to continue and change career choice. I wish there would have been more discussion about it not being a reasonable choice for me at the time as we just didn't have the information then". $8 / 14$ young adults changed their career plans because of their arthritis with managing JIA symptoms and a physically demanding role, as well as wanting to stay healthy, being the main reasons for changing career. Important aspects of employment included: "good relationships with your line manager, work you like doing and a job you can use your initiative".

Conclusions: Despite small numbers these results highlight potential current unmet vocational needs of young adults with JIA in the UK and the need for further research with this age group. There appears to be a lack of structured support within schools and universities offered to students with disabilities and/or additional needs, about work-related activities and careers. Young adults with JIA actively consider their condition whilst thinking about career opportunities and value a productive and challenging job with a good working environment, including relationships with colleagues and supervisors.

Disclosure of Interest: None declared

DOI: 10.1136/annrheumdis-2018-eular.2099

\section{AB1125 URINARY SOLUBLE CD25 AS A BIOMARKER OF ACTIVE LUPUS NEPHRITIS IN EGYPTIAN CHILDREN WITH JUVENILE SYSTEMIC LUPUS ERYTHEMATOSUS}

W.A. Hassan ${ }^{1}$, M.Y. Mahgoup ${ }^{1}$, E.G. Behiry ${ }^{2} .{ }^{1}$ Rheumatology and Rehabilitation; ${ }^{2}$ Clinical and Chemical Pathology, Benha University, Benha, Egypt

Background: Lupus nephritis $(\mathrm{LN})$ is more prevalent and severe in children than adult and considered a major predictor of poor outcome. Thus, early diagnosis and treatment is associated with better outcome. Soluble CD25 (sCD25), also known as Interleukin-2 receptor alpha chain, is a type I transmembrane protein present on activated $\mathrm{T}$ lymphocytes that play important role in the pathogenesis LN $\left[{ }^{1}\right.$

Objectives: This study aimed to measure urinary levels of SCD25 in children with juvenile systemic lupus erythematosus (JSLE) and to investigate its role as a potential biomarker of activity in LN.

Methods: We measured SCD25 using enzyme-linked immunosorbent assay in urine samples from 53 JSLE patients and in urine samples from 30 healthy controls and these levels were normalised to creatinine excretion in urine. All JSLE patients underwent thorough clinical examination and disease activity assessment using Systemic Lupus Erythematous Disease Activity Index (SLEDAI).
Systemic Lupus International Collaborating Clinics (SLICC) renal activity score ${ }^{2}$ was used to assess activity of LN.

Results: Urinary SCD25 normalised levels were highly significantly increased in JSLE patients $(278.38 \pm 133.68 \mathrm{pg} / \mathrm{mg})$ compared to urinary level in the healthy controls $(187.33 \pm 83.59 \mathrm{pg} / \mathrm{mg}), p<0.001$. Also, patients with active $L N$ had significantly higher normalised urinary sCD25 levels $(402.69 \pm 139.58 \mathrm{pg} / \mathrm{mg})$ compared to urinary level in active JSLE patients without LN $(262.18 \pm 98.35 \mathrm{pg} / \mathrm{mg})$, $\mathrm{p}=0.002$ and inactive JSLE patients $(192.7 \pm 66.4 \mathrm{pg} / \mathrm{mg}), \quad p<0.001$. In JSLE patients, urinary SCD25 normalised levels significantly correlated with SLEDAI $(r=0.48, p<0.05)$, renal SLEDAI $(r=0.61, p<0.001)$, SLICC renal activity score $(r=0.68, p<0.001)$ and $C 3(r=-0.48, p<0.001)$.

Conclusions: JSLE patients have significantly increased urinary levels of SCD25 especially in those with active LN. Urinary sCD25 levels are remarkably correlated with the renal disease activity scores suggesting that it could be a useful marker to reflect active renal involvement in JSLE patients.

\section{REFERENCES}

[1] - Gupta R, Yadav A, Misra R, Aggarwal A. Urinary sCD25 as a biomarker of lupus nephritis disease activity. Lupus 2015; Mar;24(3):273-9.

[2] - Petri M, Kasitanon N, Lee SS, Link K, Magder L, Bae SC, et al. Systemic Lupus International Collaborating Clinics (2008) Systemic lupus international collaborating clinics renal activity/response exercise. Development of a renal activity score and renal response index. Arthritis Rheum 2008; 58 (6):1784-88.

Disclosure of Interest: None declared DOI: 10.1136/annrheumdis-2018-eular.4494

\section{AB1126 NO RADIOGRAPHIC WRIST DAMAGE AFTER TARGETED TREATMENT IN JUVENILE IDIOPATHIC ARTHRITIS}

W.G. van Braak ${ }^{1}$, D. Schreurs ${ }^{2}$, P. Hissink Muller ${ }^{2,3}$, C. Nusman ${ }^{1,4}$, R. Hemke ${ }^{1}$, D. Schonenberg ${ }^{4}$, J. van den Berg ${ }^{4}$, T. Kuijpers ${ }^{4}$, Y. Koopman ${ }^{5}$, M. van Rossum ${ }^{6}$ L. van Suijlekom-Smit ${ }^{3}$, D. Brinkman ${ }^{2}$, C. Allaart ${ }^{3}$, R. ten Cate $^{2}$, M. Maas ${ }^{1}$.

${ }^{1}$ Department of Radiology, Academic Medical Center, Amsterdam; ${ }^{2}$ Department of Pediatric Rheumatology, Leiden University Medical Center, Leiden; ${ }^{3}$ Department of Pediatrics/Pediatric Rheumatology, Sophia Children's Hospital Erasmus Medical Center, Rotterdam; ${ }^{4}$ Department of Pediatric Hematology, Immunology, Rheumatology and Infectious Diseases, Emma Children's Hospital AMC, Amsterdam; ${ }^{5}$ Department of Pediatrics, Hagaziekenhuis Juliana Children's Hospital, The Hague; ${ }^{6}$ Department of Pediatric Rheumatology, Amsterdam Rheumatology and Immunology Center location Reade, Amsterdam; ${ }^{7}$ Department of Rheumatology, Leiden University Medical Center, Leiden, Netherlands

Background: Juvenile idiopathic arthritis (JIA) is characterised by chronic inflammation of the joints which can lead to structural bone damage.

Objectives: The objective of this study was to evaluate the response of new onset JIA patients to an early targeted treatment by conventional radiography. Methods: JIA patients participating in the BeSt for Kids study (NTR 1574) were eligible in case of wrist involvement at inclusion and if conventional radiographs were available at baseline or within 6 months before or after study inclusion. Follow-up radiographs of hands and wrists after 12-36 months were available for comparison. Radiographic bone damage as reflected by carpal length was assessed using the Poznanski score ${ }^{1}$, providing ' $Z$ ' as indication of the deviation from a healthy population as measured by radiometacarpal length relative to the second metacarpal length (RM/M2). BoneXpert method ${ }^{2}$ was used to automatically determine bone age and bone mineral density (BMD) of the wrist.

Abstract AB1126 - Table 1

\begin{tabular}{|c|c|c|c|c|c|}
\hline & $\begin{array}{c}\text { Baseline Z- } \\
\text { score } \\
(95 \% \mathrm{Cl})\end{array}$ & $\begin{array}{c}\text { Compared to } \\
\text { healthy } \\
\text { population }\end{array}$ & $\begin{array}{c}\text { Follow-up Z- } \\
\text { score } \\
(95 \% \mathrm{Cl})\end{array}$ & $\begin{array}{c}\text { Compared to } \\
\text { healthy } \\
\text { population }\end{array}$ & $\begin{array}{c}\text { Change } \\
\text { in Z- } \\
\text { score }\end{array}$ \\
\hline $\begin{array}{l}\text { Poznanski } \\
\text { score }\end{array}$ & $\begin{array}{c}0.047(-0.32 \\
\text { to } 0.41)\end{array}$ & $p=0.795$ & $\begin{array}{c}0.055(-0.28 \\
\text { to } 0.39)\end{array}$ & $p=0.744$ & $p=0.937$ \\
\hline BMD & $\begin{array}{c}-0.71(-1.12 \\
\text { to }-0.30)\end{array}$ & $p=0.001$ & $\begin{array}{c}-0.44(-0.75 \\
\text { to }-0.12)\end{array}$ & $p=0.008$ & $\mathrm{p}=0.032$ \\
\hline Bone age & $\begin{array}{c}-0.08(-0.44 \\
\text { to } 0.28)\end{array}$ & $p=0.651$ & $\begin{array}{c}-0.25(-0.59 \\
\text { to } 0.09)\end{array}$ & $\mathrm{p}=0.574$ & $\mathrm{p}=0.092$ \\
\hline
\end{tabular}

Results: Forty JIA (27 female) patients were evaluated for Poznanski score and BMD (mean age 7.2 \pm 3.4 years), 26 patients (15 female) were evaluated for bone age (mean age $9.3 \pm 2.2$ years). Assessed by the mean Z-score of RM/M2, we did not detect wrist damage at baseline nor at follow-up. Assessed by the mean Zscore of the bone age, we did not detect deviating bone age at baseline nor at follow-up. At baseline BMD was significantly diminished compared to healthy 
controls (Z-score $-0.71,95 \% \mathrm{Cl}=-1.12$ to -0.30$)$. BMD at follow-up improved significantly (Z-score $-0.44,95 \% \mathrm{Cl}=-0.75$ to $-0.12, \mathrm{p}=0.032)$. Results are summarised in table 1.

Conclusions: In this cohort of JIA patients treated early and targeted at inactive disease, we have detected no radiographic wrist damage at baseline or follow-up as detected by Poznanski score. BMD was significantly diminished at baseline but improved significantly after follow-up.

\section{REFERENCES:}

[1] Poznanski AK, Hernandez RJ, Guire KE, Bereza UL, Garn SM. Carpal length in children - a useful measurement in the diagnosis of rheumatoid arthritis and some congenital malformation syndromes. Radiology 1978;129:661-8.

[2] Anink J, Nusman CM, van Suijlekom-Smit LW, van Rijn RR, Maas M, van Rossum MA. Automated determination of bone age and bone mineral density in patients with juvenile idiopathic arthritis: a feasibility study. Arthritis Res Ther 2014;16:424.

Disclosure of Interest: None declared

DOI: 10.1136/annrheumdis-2018-eular.5306

\section{Other orphan diseases}

\section{AB1127 PULMONARY ARTERIAL HYPERTENSION AND POSTERIOR REVERSIBLE ENCEPHALOPATHY SYNDROME (PRES) IN A PATIENT WITH ADULT ONSET STILL'S DISEASE}

A. Khan, K. Bhamra, S. El-Ghazali, M. Adler. Rheumatology, Wexham Park Hospital, Frimley Health Foundation Trust, Slough, UK

Background: Pulmonary arterial hypertension is a rare complication of AOSD and there are only a limited number of case reports in the literature.

PRES is a rare acute neurological condition characterised by rapid onset of headache, seizures, altered consciousness, visual disturbances and usually very high blood pressure. Brain imaging characteristically shows high signal change in the subcortical white matter, predominantly in the posterior lobes which normalises within days to weeks. There are rare case reports of seizures and other neurological manifestations associated with AOSD but no published case reports of classic PRES

Objectives: To share this interesting case with our rheumatology colleagues. Methods: We present a case of 24 year old Afro-Caribbean lady, diagnosed with AOSD in December 2015, presenting with recurrent fevers, weight loss, polyarticular synovitis, small volume lymphadenopathy, evanescent urticarial rash, hyperferritinemia (3700 ug/L) and raised CRP (146 mg/L). Rheumatoid factor, ANA CCP, ENA and ANCA were negative. Infection screen was negative including blood-borne viruses and whole-body imaging was normal.

She was initially treated with pulsed Methylprednisolone $1 \mathrm{~g} \mathrm{IV}$ for 3 days followed by $40 \mathrm{mg}$ oral prednisolone. She had a good initial response (ferritin $1700 \mathrm{ug} / \mathrm{L}$ CRP $36 \mathrm{mg} / \mathrm{L}$ ), but subsequently we were unable to reduce her prednisolone below $35 \mathrm{mg}$ due to recurrence of symptoms.

She had quite a stormy course over the rest of the year with a number of hospital admissions and her ferritin running as high as 35,000 ug/L and CRP more than $200 \mathrm{mg} / \mathrm{L}$.

In February 2017 she had a further severe flare and was started on Anakinra. She initially responded well (Ferritin $400 \mathrm{ug} / \mathrm{L}, \mathrm{CRP} 3 \mathrm{mg} / \mathrm{L}$ ), but four months later started to flare again, requiring a further admission, treated with IV Methylprednisolone.

She was switched from Anakinra to Tocilizumab but was stopped after 4 doses due to poor response.

Following development of exertional dyspnoea, echocardiography and right heart catheter studies demonstrated a raised mean pulmonary artery pressure of $42 \mathrm{mmhg}$ with severe TR, right sided volume overload and a BNP of $8741 \mathrm{ng} / \mathrm{L}$ warranting referral to the regional $\mathrm{PAH}$ centre.

She also developed peripheral sensorimotor neuropathy in her lower limbs confirmed by NCS.

Results: In December 2017 she was admitted with severe shortness of breath hypoxia and a ferritin of over 15,000 ug/L. She developed seizures with status epilepticus, very high blood pressure and ended up requiring mechanical ventilation. $\mathrm{MRI}$ and CT brain were suggestive of PRES with subcortical high signal change and symmetrical vasogenic oedema in occipital and parietal lobes. She was treated in Neuro ITU with anti-epileptics, anti-hypertensives, IV hydrocortisone and Anakinra was restarted. She made a rapid and full neurological recovery with resolution of changes on her brain scans.
She continues Anakinra, and Cyclosporine $2 \mathrm{mg} / \mathrm{kg}$ body weight has been added since. She has also been started on Tadalafil $20 \mathrm{mg}$ BD for her pulmonary arteria hypertension.

Prednisolone has been tapered to $15 \mathrm{mg}$ and she is clinically well with a CRP of $26 \mathrm{mg} / \mathrm{L}$ and ferritin of $2600 \mathrm{ug} / \mathrm{L}$.
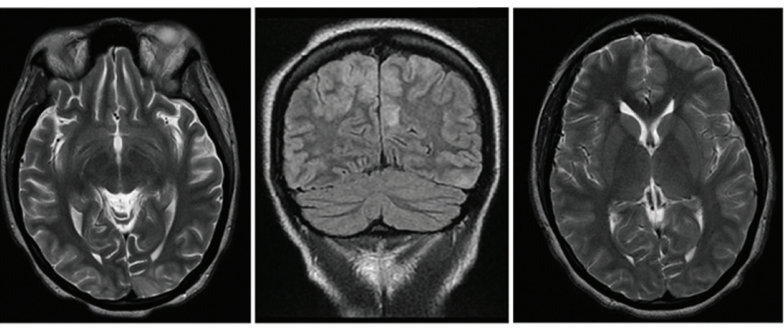

Abstract AB1127 - Figure 1

Conclusions: We present a case of life threatening AOSD complicated by pulmonary arterial hypertension, PRES and peripheral neuropathy.

She has unusually severe disease, which is quite refractory to treatment and has been associated with rare manifestations.

Disclosure of Interest: A. Khan Shareholder of: No, Grant/research support from: No, Consultant for: No, Employee of: No, Paid instructor for: No, Speakers bureau: No, K. Bhamra: None declared, S. El-Ghazali: None declared, M. Adler: None declared

DOI: 10.1136/annrheumdis-2018-eular.2434

\section{AB1128 1 EVALUATION OF SERUM VERSICAN LEVELS IN PATIENTS WITH FAMILIAL MEDITERRANEAN FEVER} (FMF)

M.E. Derin ${ }^{1}$, I. Karadağ ${ }^{1}$, A.C. Urhan ${ }^{1}$, G. Toksoylu², G. Asan ${ }^{3}$, M. Bayram ${ }^{3}$, H. O. Doğan ${ }^{4}$, M. Şahin ${ }^{4}$, A. Şahin ${ }^{1} .{ }^{1}$ Rheumatology - Internal Medicine; ${ }^{2}$ Internal Medicine; ${ }^{3}$ Internal Medicine; ${ }^{4}$ Biochemistry Department, Cumhuriyet University Medical Faculty, Sivas, Turkey

Background: Familial Mediterranean fever (FMF) is an autoinflammatory dis ease which has self-limiting inflammatory attacks placing in polyserositis. ${ }^{1}$ Versican is an extracellular proteoglycan which interacts with receptors that regulate immune system. ${ }^{2}$

Objectives: The aim of this study is to measure serum versican levels between FMF and control group.

Methods: Between June 2017 - Semptember 2017 thirty-seven FMF patients with attack-free period that following-up at Cumhuriyet University Faculty of Medicine Department of Internal Medicine Rheumatology and thirty-five healthy volunteers without any rheumatic, systemic and metabolic diseases were enrolled in this study. Clinical findings of all patients were recorded. Blood tests were examined by Elisa method in Cumhuriyet University Department of Biochemistry.

Results: The median age of the FMF patients was 33( ${ }^{19-64}$ years. Of the FMF patients, twenty-one $(56.8 \%)$ were female and sixteen $(43.2 \%)$ were male. The median age of control group was $26^{18-38}$ years. Of the control group fourteen $(40 \%)$ were female and twenty-one $(60 \%)$ were male. The median versican leve was measured as $18.3 \mathrm{ng} / \mathrm{ml}$ in FMF group and $23 \mathrm{ng} / \mathrm{ml}$ in healthy group $(p<0.05)$. There was no correlation between eritrosit sedimantation rate $(E S R)$, CRP, fibrinogen, serum amyloid-A (SAA) protein other clinical manifestations, medications and versican levels (table 1 ).

Abstract AB1128 - Table 1. Subgroup analysis in patients with FMF.

\begin{tabular}{lcc}
\hline & Serum Versican Levels $\mathrm{ng} / \mathrm{ml}$ (median) & P value \\
\hline ESR $>20 \mathrm{~mm} / \mathrm{h} n=25$ & 20.03 & \\
$\mathrm{ESR}<20 \mathrm{~mm} / \mathrm{h} n=2$ & 16.5 & .597 \\
$\mathrm{CRP}>10 \mathrm{mg} / \mathrm{L} \mathrm{n}=25$ & 19.2 & \\
$\mathrm{CRP}<10 \mathrm{mg} / \mathrm{L} \mathrm{n}=12$ & 16.5 & .713 \\
Fibrinogen $>200 \mathrm{mg} / \mathrm{dl} \mathrm{n}=9$ & 18.2 & \\
Fibrinogen $<200 \mathrm{mg} / \mathrm{dl} \mathrm{n}=28$ & 18.7 & .986 \\
$>40$ years $\mathrm{n}=15$ & 18.2 & .591 \\
$<40$ years $\mathrm{n}=22$ & 19.5 &
\end{tabular}

